\title{
SHOULDER ISOKINETIC PERFORMANCE IN HEALTHY PROFESSIONAL JUDO ATHLETES: NORMATIVE DATA
}

\section{DESEMPENHO ISOCINÉTICO DO OMBRO DE ATLETAS PROFISSIONAIS DE JUDÔ SAUDÁVEIS: DADOS NORMATIVOS}

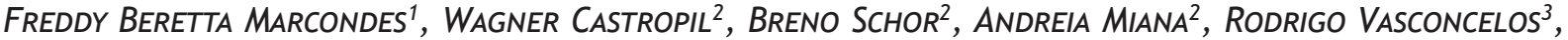 \\ MAURICIO ETCHEBEHERE ${ }^{1}$
}

1. Universidade Estadual de Campinas (Unicamp), Department of Orthopedics and Traumatology, Campinas, SP, Brazil.

2. Instituto Vita, São Paulo, SP, Brazil.

3. Instituto Wilson Mello, Núcleo de Estudos, Campinas, SP, Brazil.

\begin{abstract}
Objective: To evaluate normative data of shoulder isokinetic strength in healthy professional judo athletes. Methods: Cross-sectional study with 20 professional male and female athletes (10 female), evaluated with an isokinetic dynamometer. The strength assessment was carried out in external and internal rotation, flexion, extension, adduction and abduction. All data collected on muscle torque were normalized with body mass index. Results: Athletes demonstrated higher peak torque and joint work in shoulder adduction, abduction, flexion, and extension for the dominant limb compared to the non-dominant limb $(p<0.05)$, with most of these deficits below $10 \%$. Shoulder internal/external rotation ratios for male and female athletes had no significant differences between dominant and non-dominant sides, demonstrating values at $60 \%$ of 49.4 \pm 7.2 on the dominant side of males and $49.1 \pm 4.9$ for females. Conclusion: The normative data are described to assist during treatment, return to sport and injury prevention. Level of evidence IV, cross-sectional study.
\end{abstract}

Keywords: Shoulder. Muscle Strength Dynamometer. Judo. Martial Arts.

\section{RESUMO}

Objetivo: Avaliar dados normativos da força isocinética do ombro de judocas profissionais, saudáveis. Métodos: Estudo transversal com 20 atletas profissionais de ambos os sexos (dez mulheres) avaliados com dinamômetro isocinético. A avaliação da força foi realizada em rotação externa e interna, flexão, extensão, adução e abdução. Todos os dados coletados do torque muscular foram normalizados com o índice de massa corporal. Resultados: Os atletas demonstraram maior pico de torque e trabalho articular em adução, abdução, flexão e extensão do ombro para o membro dominante, comparado ao contralateral $(p<0,05)$, com a maioria desses défices abaixo de $10 \%$. As razões de rotação interna/externa do ombro para atletas de ambos os sexos não apresentaram diferenças significativas entre 0 lados dominante e não dominante, demonstrando valores a $60 \%$ de 49,4 $\pm 7,2$ no lado dominante dos homens e 49,1 $\pm 4,9$ no das mulheres. Conclusão: Os dados normativos são descritos para auxiliar durante o tratamento, o retorno ao esporte e a prevenção de lesões. Nível de evidência IV, estudo transversal.

Descritores: Ombro. Dinamômetro de Força Muscular. Judô. Artes Marciais.

Citation: Marcondes FB, Castropil W, Schor B, Miana A, Vasconcelos R, Etchebehere M. Shoulder isokinetic performance in healthy professional judo athletes: normative data. Acta Ortop Bras. [online]. 2019;27(6):308-12. Available from URL: http://www.scielo.br/aob.

\section{INTRODUCTION}

Judo is a combat sport that demands high intensity from almost all of the joints in the body. The athlete attempts to throw the opponent onto his/her back or to control the opponent on the ground by pinning techniques. It is a common sport, entering the Olympic Games for men in 1964 as a demonstration sport, and officially in 1972 for men and in 1992 for women. ${ }^{1}$ According to the International Judo Federation, there are 20 million judo practitioners worldwide, ${ }^{2}$ with relatively high risk of injury. ${ }^{3}$

The technical of combat depends on many aspects during the fight, but in all situations, there is a great demand on the shoulders. According to the data published by Pocecco et $\mathrm{al}^{3}$ shoulder injuries are common in judo practice, and the second most common injury in this sport. Similarly, Cierna et $\mathrm{al}^{4}$ found that shoulder injuries are the second most common injuries in elite European judo competitions. Acromioclavicular joint dislocation, rotator cuff tendinopathy and shoulder dislocation are the most common injuries of the shoulder. ${ }^{3}$ The judoka frequently transfers energy from the trunk to the upper limbs during a continuous closed chain that overloads the shoulder joint. This is one of the reasons why judo movement is very demanding on shoulders; in throwing movements, to control the falls to the ground and to apply pin or armlock techniques. Not surprisingly, most of the injuries at the shoulder joint come from a throwing movement or from being thrown, ${ }^{5}$ with no difference in the localization of injuries between male and female judokas. ${ }^{5}$

All authors declare no potential conflict of interest related to this article.

Work conducted at the Universidade Estadual de Campinas (UNICAMP) and at Instituto Vita, São Paulo, SP, Brazil.

Correspondence: Freddy Marcondes. Rua Tessália Vieira de Camargo, 126. Cidade Universitária, Campinas, SP, Brazil. berettafisio@yahoo.com.br 
There are several studies that describe the normative data of isokinetic shoulder tests in different populations, like tennis players, ${ }^{6}$ baseball players ${ }^{7}$ and swimmers. ${ }^{8}$ This data helps to determine the safest time for an athlete's return to sport, preventing new injuries. However, there is a lack of normative data on isokinetic strength of judoka's shoulders and this is important information during the athlete's treatment and a criterion to return to the sport.

Thus, the purpose of this study was to evaluate the performance of the shoulders of 20 asymptomatic, elite judo athletes (10 females), who are members of the national judo team in international competitions.

\section{MATERIALS AND METHODS}

Brazilian national judo team athletes were screened as possible study participants during a pre-season period. All athletes are competitors at the international level, with at least 10 years of practice. All the athletes were volunteers in the study and signed the informed consent form approved by the Institutional Review Board, under number 1.241.261. Inclusion criteria: high level athlete, asymptomatic for at least six months; no history of surgical treatment of the upper limbs or cervical spine. Exclusion criteria: previous shoulder and/or cervical spine surgery; previous humerus, scapula and/or clavicle fracture. Twenty asymptomatic high-performance competitive judo athletes were enrolled in the study. The sample size was defined by convenience. A single physiotherapist with 10 years of practice in isokinetic assessment conducted the tests in the athletes, using the same machine. An isokinetic dynamometer was used for the tests, (Figure 1) Cybex/ HUMAC NORM Extremity System (Henley Healthcare, serial no. A8814). The machine had been calibrated according to the manufacturer's instructions.

Prior to the assessment, the athletes performed a warm-up consisting of riding for 10 minutes on a stationary bicycle. Before each test, the judokas went through a familiarization process, so that the evaluation method was better understood. The familiarization was done initially in 3 repetitions at $60 \%$, followed by the official test performed in 5 repetitions at $60 \%$ s. The athlete then passed the familiarization process at $180 \%$ speed, performing 4 repetitions at this speed, followed by the official test consisting of 15 repetitions at $180 \%$ s. There was a 60 -second rest between the familiarization series and the official tests. There was also a rest of approximately 5 minutes between flexion/extension, abduction/adduction and internal/external rotation tests, to make the necessary modifications to the machine for the correct performance of the tests. All evaluations were performed concentrically. The evaluation methods and the exact sequence are described as follows.

The flexion/extension tests were performed according to the manufacturer's protocol, with the athlete in supine position and the axis of rotation of the shoulder joint aligned with the axis of rotation of the dynamometer arm. The handgrip and lever arm of the dynamometer were adjusted to allow the elbow to remain in full extension. ${ }^{9}$ Total range of motion used in the test was between $0^{\circ}$ and $120^{\circ}$ of flexion. Belts were used to stabilize the athletess scapular and pelvic girdle. The hips and knees were kept in a neutral position, that is, at 0 degree. The gravity correction was performed with the athlete's arms relaxed at $80^{\circ}$ of flexion.

The abduction/adduction movements were evaluated in the sitting position, and the trunk and pelvis were stabilized with the belts. The arm was positioned in the coronal plane, in neutral rotation and with the elbow in full extension. The axis of rotation of the humeral head was aligned with the axis of rotation of the dynamometer lever arm. The total range of motion allowed was $0^{\circ}$ to $90^{\circ} .^{10}$ Gravity correction was performed with the athlete's arms relaxed at $80^{\circ}$ of abduction. The test of the external/internal rotation movements was performed with the athlete standing on the monorail deck, feet shoulder-width apart

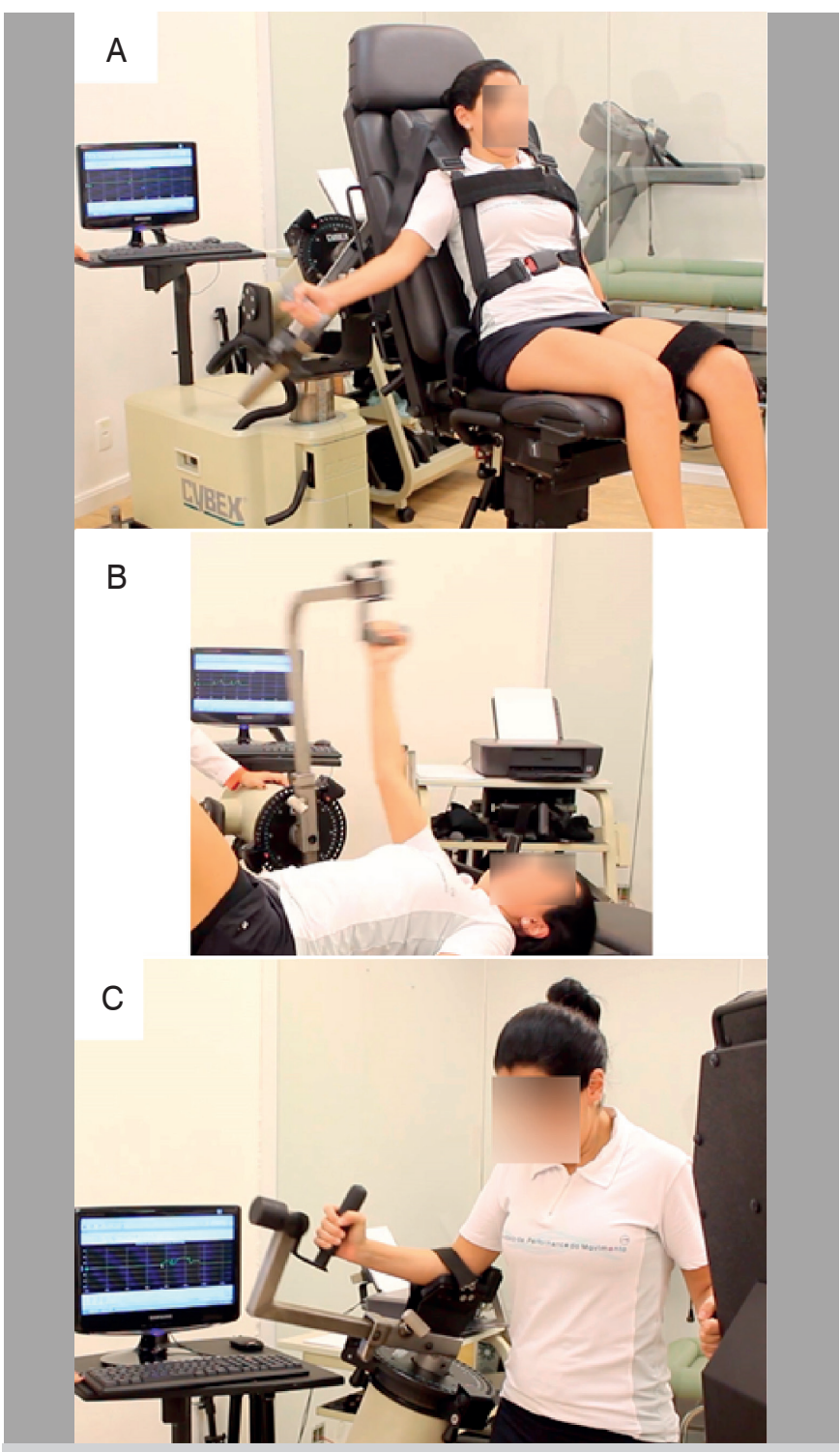

Figure 1. Illustrative figures of the shoulder isokinetic testing in $60 \%$ and 180\%: (A) abduction/ adduction; (B) flexion/ extension; (C) Internal/ external rotation.

and with knees slightly flexed. The height of the dynamometer was adjusted to allow a position of $45^{\circ}$ of abduction and $30^{\circ}$ in horizontal adduction (scapular plane). The rotation axis of the dynamometer was aligned to the rotation axis of the glenohumeral joint. The elbow was supported on a stabilizer pad and secured with an adhesive strap in $90^{\circ}$ of flexion. The lever arm was adjusted to the length of the athlete's forearm, in neutral position allowing an appropriated handgrip. ${ }^{11,12}$ Gravity correction was performed with the athlete's arms relaxed at $60^{\circ}$ of external rotation. The total range of motion allowed in the test was $60^{\circ}$ of external rotation and $45^{\circ}$ of internal rotation. The athlete was informed that trunk rotation movements would not be allowed, and the evaluator was aware of possible compensatory movements. All data from muscle torque were normalized with body mass using the formula: (Muscle torque/body mass) x 100. ${ }^{11}$ After verifying the normality of the data distribution, a sample t-test was used to compare limbs: dominant and non-dominant. For the clinical analyses findings, the effect size was calculated ( $d$ of Cohen), where the amplitudes of $<0.31,0.31-0.70$ and $>0.70$ were defined as small-size effect, moderate and broad, respectively (Cohen, 1988). 
The data is shown as average \pm standard deviation and has a 95\% reliability interval for the average differences. The level of significance adopted in the entire analyses was $5 \%(P<0.05)$. The analyses were conducted using PASW statistic 18.0 software, SPSS Inc., Chicago, USA. ${ }^{13}$

\section{RESULTS}

The demographic data of the sample is demonstrated in Table 1. Men and women demonstrated higher peak torque and joint work for all the movements analyzed (shoulder adduction, abduction, flexion, and extension) for the dominant limb in comparison to the

Table 1. Demographic data from the enrolled athletes.

\begin{tabular}{c|c|c|c}
\hline Parameter & Men $(n=10)$ & Women $(n=10)$ & Total $(n=20)$ \\
\hline Age $($ years old $)$ & $26 \pm 4$ & $21 \pm 2$ & $23 \pm 4$ \\
\hline Weight $(\mathrm{kg})$ & $82.7 \pm 12.5$ & $70.2 \pm 15.1$ & $76.5 \pm 14.9$ \\
\hline Dominant limb & $50 \%$ Right & $50 \%$ Right & $50 \%$ Right \\
\hline
\end{tabular}

Data is shown as mean values \pm standard deviation. contralateral side $(\mathrm{P}<0.05)$. The exception was for the adductor peak torque at $180 \%$ s and joint work abductor at $60 \%$ s $(P=0.098$ and $P=0.092)$ for men, and extensor peak torque at $180 \%$ for women $(P=0.018)$. (Table 2; Table 3)

Table 4 shows the differences between male and female shoulder performance on isokinetic tests. Table 5 shows the external and internal rotation ratios for males and females, for both shoulders.

\section{DISCUSSION}

The objective of the current study was to analyze the normative parameters of shoulder strength and performance in international level, high performance judo athletes. The isokinetic testing at speeds of $60 \%$ and $180 \%$ s were chosen because are better to detect deficits that may represent risk factors for lesions, especially in agonist/ antagonist ratio analysis. ${ }^{12}$ According to Codine, speeds above $180^{\circ}$ s may be difficult to achieve, even for professional athletes. ${ }^{14}$ One of the few study published about the theme, Ghrairi et al, ${ }^{15}$ evaluated 10 male professional judo athletes from the Tunisian

Table 2. Peak Torque (\% Body Mass) and Total Joint Work (J) for Male Judo Athletes ( $n=10)$.

\begin{tabular}{|c|c|c|c|c|c|c|c|}
\hline Parameter & Dominant limb & Non-dominant limb & Deficit (\%) & Difference & IC 95\% & Effect (d) & P Value \\
\hline \multicolumn{8}{|l|}{ Peak torque } \\
\hline Abduction $60 \%$ & $86.1 \pm 2.5$ & $81.8 \pm 3.9$ & 5.4 & 4.4 & $2.6-6.1$ & 1.36 & 0.001 \\
\hline Abduction $180 \%$ & $163.5 \pm 25.4$ & $154.5 \pm 25.1$ & 5.9 & 9.1 & $5.3-12.8$ & 0.36 & 0.001 \\
\hline Adduction $60 \% \mathrm{~s}$ & $111.3 \pm 10.9$ & $105.7 \pm 11.2$ & 5.3 & 5.6 & $3.4-7.7$ & 0.50 & 0.001 \\
\hline Adduction $180 \%$ s & $183.3 \pm 36.4$ & $177.5 \pm 28.3$ & 3.3 & 5.8 & $-0.4-11.9$ & 0.18 & 0.098 \\
\hline Flexion $60 \%$ & $102.3 \pm 7.4$ & $96.7 \pm 7.7$ & 5.8 & 5.6 & $4.0-7.1$ & 0.74 & $<0.001$ \\
\hline Flexion $180 \% / \mathrm{s}$ & $172.1 \pm 17.9$ & $164.1 \pm 16.5$ & 4.8 & 7.9 & $4.1-11.8$ & 0.46 & 0.003 \\
\hline Extension $60 \%$ & $126.8 \pm 11.6$ & $119.1 \pm 13.3$ & 6.5 & 7.7 & $4.8-10.6$ & 0.62 & 0.001 \\
\hline Extension $180^{\circ} / \mathrm{s}$ & $215.9 \pm 19.2$ & $208.5 \pm 19.8$ & 3.5 & 7.3 & $4.0-10.6$ & 0.37 & 0.002 \\
\hline External rotation $60 \% / \mathrm{s}$ & $40.1 \pm 6.5$ & $35.7 \pm 5.3$ & 12.3 & 4.4 & $1.9-6.9$ & 0.75 & 0.007 \\
\hline External rotation $180 \% \mathrm{~s}$ & $69.2 \pm 7.8$ & $64.7 \pm 8.3$ & 7.0 & 4.5 & $2.1-7.0$ & 0.56 & 0.006 \\
\hline Internal rotation $60 \% \mathrm{~s}$ & $81.4 \pm 8.6$ & $76.7 \pm 6.5$ & 6.1 & 4.7 & $2.4-7.0$ & 0.62 & 0.003 \\
\hline Internal rotation $180 \% \mathrm{~s}$ & $161.5 \pm 12.5$ & $156.4 \pm 13.5$ & 3.3 & 5.1 & $3.2-7.1$ & 0.39 & 0.001 \\
\hline \multicolumn{8}{|l|}{ Total Joint work } \\
\hline Abduction $60 \%$ s & $93.4 \pm 13.8$ & $89.9 \pm 13.5$ & 3.9 & 3.5 & $-0.1-7.1$ & 0.26 & 0.092 \\
\hline Adduction $60 \%$ & $115.4 \pm 22.1$ & $112.1 \pm 22.2$ & 2.9 & 3.3 & $0.8-5.8$ & 0.15 & 0.031 \\
\hline Flexion $60 \%$ & $100.7 \pm 23.2$ & $97.0 \pm 22.9$ & 3.8 & 3.7 & $0.8-6.6$ & 0.16 & 0.033 \\
\hline Extension $60 \% \mathrm{~s}$ & $121.4 \pm 24.6$ & $116.6 \pm 25.4$ & 4.1 & 4.8 & $1.4-8.2$ & 0.19 & 0.021 \\
\hline External rotation $60 \% \mathrm{~s}$ & $45.6 \pm 1.5$ & $40.7 \pm 10.7$ & 12.0 & 4.9 & $3.0-6.8$ & 0.44 & 0.001 \\
\hline Internal rotation $60 \% \mathrm{~s}$ & $84.6 \pm 28.4$ & $78.2 \pm 28.1$ & 8.2 & 6.4 & $3.3-9.5$ & 0.23 & 0.003 \\
\hline
\end{tabular}

IC 95\%: Limits with 95\% confidence for the difference between dominant and non-dominant limbs.

Table 3. Peak Torque (\% Body Mass) and Total Joint Work $(\mathrm{J})$ for Female Judo Athletes $(\mathrm{n}=10)$

\begin{tabular}{|c|c|c|c|c|c|c|c|}
\hline Parameter & Dominant limb & Non-dominant limb & Deficit (\%) & Difference & IC 95\% & Effect (d) & P Value \\
\hline \multicolumn{8}{|l|}{ Peak Torque } \\
\hline Abduction $60 \%$ s & $71.0 \pm 11.9$ & $64.5 \pm 8.4$ & 10.1 & 6.5 & $2.8-10.2$ & 0.64 & 0.008 \\
\hline Abduction $180 \% \mathrm{~s}$ & $110.1 \pm 18.0$ & $102.2 \pm 22.4$ & 7.8 & 7.9 & $4.7-11.1$ & 0.39 & 0.001 \\
\hline Adduction $60 \%$ s & $76.2 \pm 5.8$ & $69.7 \pm 5.4$ & 9.4 & 6.5 & $3.5-9.6$ & 1.17 & 0.002 \\
\hline Adduction $180 \% \mathrm{~s}$ & $114.5 \pm 12.4$ & $106.6 \pm 15.8$ & 7.4 & 7.9 & $4.0-11.8$ & 0.56 & 0.003 \\
\hline Flexion $60 \% \mathrm{~s}$ & $72.4 \pm 8.2$ & $67.7 \pm 8.0$ & 6.9 & 4.7 & $1.8-7.6$ & 0.58 & 0.012 \\
\hline Flexion $180 \% / \mathrm{s}$ & $112.9 \pm 20.2$ & $106.8 \pm 20.4$ & 5.7 & 6.1 & $1.9-10.3$ & 0.30 & 0.020 \\
\hline Extension $60 \% \mathrm{~s}$ & $93.1 \pm 9.9$ & $87.7 \pm 9.3$ & 6.1 & 5.4 & $0.7-10.0$ & 0.56 & 0.050 \\
\hline Extension $180 \% \mathrm{~s}$ & $145.1 \pm 14.1$ & $139.5 \pm 16.9$ & 4.0 & 5.6 & $-2.0-13.2$ & 0.36 & 0.180 \\
\hline External rotation $60 \% / \mathrm{s}$ & $33.3 \pm 3.3$ & $29.6 \pm 5.0$ & 12.6 & 3.7 & $0.9-6.5$ & 0.90 & 0.029 \\
\hline External rotation $180 \% \mathrm{~s}$ & $55.5 \pm 5.3$ & $50.2 \pm 6.1$ & 10.5 & 5.3 & $3.9-6.6$ & 0.93 & $<0.001$ \\
\hline Internal rotation $60 \% \mathrm{~s}$ & $67.5 \pm 4.7$ & $63.0 \pm 5.5$ & 7.1 & 4.5 & $2.6-6.3$ & 0.88 & 0.001 \\
\hline Internal rotation $180 \% / \mathrm{s}$ & $124.3 \pm 12.1$ & $117.1 \pm 12.2$ & 6.1 & 7.2 & $4.7-9.7$ & 0.59 & $<0.001$ \\
\hline \multicolumn{8}{|l|}{ Total Joint work } \\
\hline Abduction $60 \% / s$ & $65.2 \pm 21.4$ & $61.6 \pm 21.6$ & 5.8 & 3.6 & $1.9-5.3$ & 0.17 & 0.002 \\
\hline Adduction $60 \% / \mathrm{s}$ & $83.0 \pm 25.7$ & $78.0 \pm 23.7$ & 6.4 & 5.0 & $1.4-8.6$ & 0.20 & 0.025 \\
\hline Flexion $60 \% \mathrm{~s}$ & $63.5 \pm 14.2$ & $59.7 \pm 14.8$ & 6.4 & 3.8 & $2.4-5.2$ & 0.26 & $<0.001$ \\
\hline Extension $60^{\circ} / \mathrm{s}$ & $78.7 \pm 15.3$ & $72.4 \pm 18.0$ & 8.7 & 6.3 & $2.4-10.2$ & 0.38 & 0.012 \\
\hline External rotation $60 \% \mathrm{~s}$ & $32.4 \pm 7.1$ & $28.0 \pm 6.9$ & 15.7 & 4.4 & $3.1-5.7$ & 0.63 & $<0.001$ \\
\hline Internal rotation $60^{\circ} / \mathrm{s}$ & $62.4 \pm 13.9$ & $57.7 \pm 13.1$ & 8.1 & 4.7 & $3.2-6.2$ & 0.35 & $<0.001$ \\
\hline
\end{tabular}


Table 4. Peak Torque (\% Body Mass) and Total Joint Work (J) comparison between male and female judo athletes.

\begin{tabular}{|c|c|c|c|c|c|c|}
\hline Parameter & Male peak torque (mean) & $\begin{array}{l}\text { Female peak } \\
\text { torque (mean) }\end{array}$ & Difference (\%) & Difference & IC 95\% & $\mathrm{P}$ Value \\
\hline \multicolumn{7}{|l|}{ Peak torque } \\
\hline Abduction $60^{\circ} / \mathrm{s}$ & 83.9 & 67.8 & 19.3 & 16.2 & $9.3-23.0$ & $<0.001$ \\
\hline Abduction $180 \%$ s & 159.0 & 106.2 & 33.2 & 52.8 & $31.5-74.2$ & $<0.001$ \\
\hline Adduction $60 \%$ & 108.5 & 73.0 & 32.8 & 35.6 & $27.6-43.5$ & $<0.001$ \\
\hline Adduction $180 \%$ s & 180.4 & 110.6 & 38.7 & 69.8 & $46.4-93.1$ & $<0.001$ \\
\hline Flexion $60 \%$ & 99.5 & 70.1 & 29.5 & 29.4 & $22.2-36.5$ & $<0.001$ \\
\hline Flexion $180 \% / \mathrm{s}$ & 168.1 & 109.9 & 34.6 & 58.2 & $40.8-75.6$ & $<0.001$ \\
\hline Extension $60 \%$ & 123.0 & 90.4 & 26.5 & 32.6 & $22.6-42.6$ & $<0.001$ \\
\hline Extension $180 \% \mathrm{~s}$ & 212.2 & 142.3 & 32.9 & 69.9 & $53.9-85.8$ & $<0.001$ \\
\hline External rotation $60 \% \mathrm{~s}$ & 37.9 & 31.5 & 16.9 & 6.4 & $2.0-10.8$ & 0.007 \\
\hline External rotation $180 \% \mathrm{~s}$ & 67.0 & 52.8 & 21.0 & 14.1 & $7.7-20.5$ & $<0.001$ \\
\hline Internal rotation $60 \%$ & 79.0 & 65.3 & 17.5 & 13.8 & $7.9-19.7$ & $<0.001$ \\
\hline Internal rotation $180^{\circ} / \mathrm{s}$ & 158.9 & 120.7 & 24.1 & 38.3 & $26.6-50.0$ & $<0.001$ \\
\hline \multicolumn{7}{|l|}{ Total Joint work } \\
\hline Abduction $60^{\circ} / \mathrm{s}$ & 113.9 & 89.6 & 21.3 & 24.3 & $0.5-48.1$ & 0.046 \\
\hline Adduction $60^{\circ} / \mathrm{s}$ & 137.7 & 113.7 & 17.4 & 24.0 & $6.8-41.2$ & 0.009 \\
\hline Flexion $60 \%$ & 119.5 & 88.2 & 26.2 & 31.3 & $15.9-46.7$ & $<0.001$ \\
\hline Extension $60 \%$ & 143.9 & 107.9 & 25.1 & 36.1 & $22.1-50.1$ & $<0.001$ \\
\hline External rotation $60 \% \mathrm{~s}$ & 52.0 & 43.1 & 17.1 & 8.9 & $1.8-15.9$ & 0.017 \\
\hline Internal rotation $60 \% \mathrm{~s}$ & 96.8 & 85.6 & 11.6 & 11.2 & $-4.6-27.0$ & 0.153 \\
\hline
\end{tabular}

IC 95\%: Limits with 95\% confidence for the difference between male and female

Table 5. External Rotation/Internal Rotation Ratio (in \%) for Male and Female Judo Athletes on Dominant and Non-dominant Limbs $(n=20)$.

\begin{tabular}{c|c|c|c}
\hline & Ratio ER / IR Dominant & Ratio ER / IR Non-dominant & P Value \\
\hline Male 60\% & $49.4 \pm 7.2$ & $46.6 \pm 6.4$ & 0.524 \\
\hline Male $180 \% \mathrm{~s}$ & $42.9 \pm 3.7$ & $41.6 \pm 5.1$ & 0.533 \\
\hline Female 60\% & $49.1 \pm 4.9$ & $47.3 \pm 8.3$ & 0.554 \\
\hline Female $180 \% \mathrm{~s}$ & $44.8 \pm 3.2$ & $42.8 \pm 4.7$ & 0.299 \\
\hline
\end{tabular}

IC 95\%: Limits with 95\% confidence for the difference between dominant and non-dominant limbs.

national team. They demonstrated that the peaks of internal and external rotation muscles torque $(60 \%$ s and $120 \%$ s) were higher on the dominant shoulder $(84 \mathrm{~N} / \mathrm{m}$ versus $71 \mathrm{~N} / \mathrm{m}$ for internal rotation and $34.7 \mathrm{~N} / \mathrm{m}$ versus $29 \mathrm{~N} / \mathrm{m}$ for external rotation). The current study showed that both men and women athletes presented a higher peak muscle torque on their dominant side on nearly all of the movements. The exceptions were for adductor peak torque at $180 \%$ s and adductor joint work at $60 \% \mathrm{~s}(\mathrm{P}=0.098$ and $\mathrm{P}=0.092)$ for men, and extensor peak torque $180 \%$ s for women $(P=0.180)$. In the present study, athletes were evaluated on speeds of $60 \%$ and $180 \%$, differing from Ghrairi et al, ${ }_{15}^{15}$ which evaluated at $60 \%$ and $120 \%$ s. Moreover, Ghrairi et $\mathrm{al}^{15}$ did not normalize muscle force production with athlete's body weight.

Furthermore, when concentric internal and external muscle torque rotation ratios are analyzed, Ghrairi et $\mathrm{al}^{15}$ measured these values at $90 \%$ s and $180 \%$ s, and observed ratios of $36.3 \pm 5.2$ and $35.4 \pm 4.1$ on the dominant side of male athletes, respectively. On the non-dominant side, the values observed were $46.8 \pm 4.9$ and $44.1 \pm 4.3$, respectively, showing that on the dominant side the external rotation torque is lower. Differently, in our study we found that male judo athletes demonstrated higher ratios (measured at $60 \%$ and $180 \%$ s) of $49.4 \pm 7.2$ and $42.9 \pm 3.7$ on the dominant side, respectively. This different could happened because the athletes performed the tests in seated position in Ghrairi study, and we performed the internal and external rotation tests in standing position. Maybe in standing position the athletes performed more external rotation torque, raising the ratio value.

Considering external and internal rotation ratios, in our study the female judo athletes demonstrated external rotation/internal rotation ratios of $49.1 \pm 4.9$ and $44.8 \pm 3.2$ on the dominant side when evaluated at $60 \%$ s and $180 \%$ s, respectively. (Table 5) On the non-dominant side, the female athletes obtained ratios of $47.3 \pm 83$ and $42.8 \pm 4.7$ when evaluated at $60 \%$ s and $180 \%$, respectively. Following the same pattern as the male evaluations, there were no significant differences on the external rotation/internal rotation ratios comparing the dominant side to the non-dominant side at $60 \%$ and $180 \%$, as shown in Table $5(P=0.0554$ and $P=0.299$, respectively). These ratio values between $42 \%$ and $49 \%$ represents that in healthy shoulders of judo athletes the external rotation torque is almost the half of internal rotation. It can be a normal adaptation of the judo practice in high level athletes and probably a normative data for this shoulder performance measure.

When we compared the dominant side with the non-dominant side, we observed that the deficits did not surpass a difference of $10 \%$ in most cases, except for external rotation peak torque value and joint work at $60 \%$ for men. (Table 2) Female judo,kas showed differences between sides below $10 \%$, except in abduction and external rotation peak torque at $60 \% \mathrm{~s}$, external rotation peak torque at $180 \%$ s and external rotation total joint work at $60 \%$ s. (Table 3 ) On the other hand, Drid et $\mathrm{al}^{16} \mathrm{compared}$ external and internal rotation peak torque values between the dominant side and non-dominant side and they did not observe any differences in European judo athletes that compete at an international level.

When we evaluated the ratio between abductors and adductors, we observed that male athletes obtained results close to $77 \%$ and $89 \%$ at $60 \%$ and $180 \%$ s, respectively. For female athletes, the values of the ratio between abductors and adductors were approximately $93 \%$ and $96 \%$ at $60 \%$ s and $180 \%$ s, respectively. In the studies of McMaster et al, ${ }^{17,}, 18$ the ratio founded were close to $50 \%$ when evaluated at $30 \% / \mathrm{s}$ and $180 \%$ in water polo athletes and swimmers, showing that the adduction strength may be twice as large as abduction. Different from judokas, polo athletes use more adduction movement to keep their upper bodies out of the water, like swimmers that needs more adduction strength to move their bodies forward.

When the flexion and extension torque are compared, Alderink \& Kuck $^{19}$ evaluated baseball players (pitchers) and found values close to $50 \%$ when evaluated at $90 \%$ s in flexion and extension movements, while in judokas we observed values close to $80 \%$ at $60 \%$ in both genders. These results showed that healthy judokas produce approximately $20 \%$ more torque in extension than flexion. 
When the values of external and internal rotation ratios are analyzed, McMaster et $\mathrm{al}^{17}$ found ratio values close to $57 \%$ and $52 \%$ at $30 \%$ and $180 \%$ s, respectively, in water polo athletes. Edouard et al. ${ }^{20}$ studied the values of external rotation/internal rotation ratios in professional female handball athletes, and found values close to $71 \%$ on the dominant side. In our study, we observed values close to $49 \%$ and $42 \%$ at $60 \%$ s and $180 \%$ s, respectively, for male judokas. For the female athletes we found values close to $49 \%$ and $44 \%$ at $60 \%$ and $180 \%$ s, respectively. In our studies we found values of agonist/ antagonist ratios different from other high-performance sports, showing that the practice of high-performance judo generates specific adaptations of the shoulders. However, it is not possible to say whether these characteristics may predispose to injury in judoka's shoulders in the long term. Once the external rotation torque in judokas is almost the half of internal rotation, maybe the external rotation strengthening can be used to avoid symptoms. Male judokas produce more muscular torque in all the movements analyzed, when compared with females. (Table 4) However, when the external/internal rotation ratio is compared, there's no significant difference between males and females. (Table 5) There is no difference in external/internal rotation between dominant and non-dominant sides. (Table 5)
This study demonstrates limitations, like the sample size (20 asymptomatic international level athletes were studied). However, judo is a physical contact sport in which a high demand on the shoulder is required. That's why is difficult to find high-level competitors that do not refer pain in the shoulder for at least 6 months. Moreover, this study has the biggest sample of normative data analyzed for judo athletes in both genders, publish at this time. The internal and external rotations were evaluated with the athletes in orthostatic position, thus allowing trunk compensation, making it difficult to compare with other tests in the sitting position. However, other studies evaluated athletes and non-athletes in the standing position ${ }^{11,12}$ and observed that the method is reproducible and reliable. Another limitation was the absence of height and body mass index of all the athletes, but these data were not included since the category divisions are based in the body weight.

\section{CONCLUSIONS}

From the normative data of this study it was possible to report the normal performance of all shoulder movements of high-level healthy judo athletes. Such data can be used as criteria for discharge following treatment and as reference values in pre-season evaluation of judo athletes.

AUTHORS' CONTRIBUTIONS: Each author made significant individual contributions to this manuscript. FM (0000-0002-0995-608X)*: designed the study methodology, performed the statistical analysis and handled manuscript production; WC (0000-0001-8762-450X)* designed the study methodology, assessed the subjects enrolled in the study and reviewed the article; BS (0000-0002-6870-2936)*: assessed the subjects enrolled in the study and handled manuscript production; AM (0000-0002-0467-9415)*: designed the study methodology, collected the data for isokinetic evaluation and reviewed the article; RV (0000-00033404-7926)*: designed the study methodology, assessed the subjects enrolled in the study and handled manuscript production; ME (0000-0002-5176-2369)*: manuscript production and revision. *ORCID (Open Researcher and Contributor ID).

\section{REFERENCES}

1. Harmer PA. Judo. In: Caine DJ, Harmer PA, Schiff MA, eds. Epidemiology of Injury in Olympic Sports. Oxford, UK: Wiley-Backwell; 2010. p.161-75.

2. International Judo Federation. [Accessed on March 8, 2019]. Available in: http://www.ijf.org.

3. Pocecco E, Ruedl G, Stankovic N, Sterkowicz S, Del Vecchio FB, Gutiérrez-Garcia $\mathrm{C}$, et al. Injuries in judo: a systematic literature review including suggestions for prevention. Br J Sports Med. 2013;47(3):1139-43

4. Cierna D, Stefanovsky M, Matejová L, Lystad RP. Epidemiology of competition injuries in elite European judo athletes: a prospective cohort study. Clin J Sports Med. 2017; [Epub ahead of print].

5. Cynarski WJ, Kudlacz M. Injuries in martial arts and combat sports - a comparative study. Arch Budo. 2008;4:91-7.

6. Niederbracht $Y$, Shim AL. Concentric internal and eccentric external fatigue resistance of the shoulder rotator muscles in female tennis players. $\mathrm{N} \mathrm{Am} \mathrm{J}$ Sports Phys Ther. 2008;3(2):89-94.

7. Codine P, Bernard PL, Pocholle M, Benaim C, Brun V. Influence of sports discipline on shoulder rotator cuff balance. Med Sci Sports Exerc. 1997;29(11):1400-5.

8. Beach ML, Whitney SL, Dickoff-Hoffman S. Relationship of shoulder flexibility, strength, and endurance to shoulder pain in competitive swimmers. J Orthop Sports Phys Ther. 1992;16(6):262-8.

9. Yen D. Limitations of isokinetic testing to determine shoulder strength after rotator cuff repair. lowa Orthop J. 2005;25:141-4

10. Camargo PR, Avila MA, Albuquerque-Sendín F, Asso NA, Hashimoto LH, Salvini TF. Eccentric training for shoulder abductors improves pain, function and isokinetic performance in subjects with shoulder impingement syndrome: a case series. Rev Bras Fisioter. 2012;16(1):74-83.
11. Ellenbecker TS, Davies GJ. The application of isokinetics in testing and rehabilitation of the shoulder complex. J Athl Train. 2000;35(3):338-50.

12. Holt KL, Raper DP, Boettcher CE, Waddington GS, Drew MK. Hand-held dynamometry strength measures for internal and external rotation demonstrate superior reliability, lower minimal detectable change and higher correlation to isokinetic dynamometry than externally-fixed dynamometry of the shoulder. Phys Ther Sport. 2016;21:75-81.

13. Cohen J. Statistical Power Analysis for the Behavioral Sciences (2nd ed.) Hillsdale, NJ: Lawrence Erlbaum Associates, Publishers; 1988. p. xxi, 567.

14. Codine P, Bernard PL, Pocholle M, Herisson C. Isokinetic strength measurement and training of the shoulder: methodology and results. Ann Readapt Med Phys. 2005;48(2):80-92.

15. Ghrairi M, Hammouda O, Malliaropoulos N. Muscular strength profile in Tunisian male national judo team. Muscle Ligaments Tendons J. 2014;4(2):149-53.

16. Drid P, Casals C, Mekic A, Radjo I, Stojanovic M, Ostojic SM. Fitness and anthropometric profiles of international vs. national judo medalists in half-heavyweight category. J Strength Cond Res. 2015;29(8):2115-21.

17. Mc Master WC, Long SC, Caiozzo VJ. Isokinetic torque imbalances in rotator cuff of elite water polo players. Am J Sports Med. 1991;19(1):72-5.

18. Mc Master WC, Long SC, Caiozzo VJ. Torque changes in swimming athletes. Am J Sports Med. 1992;20(3):323-7.

19. Alderink GJ, Kuck DJ. Isokinetic shoulder strength of high school and college-aged pitchers. J Orthop Sports Phys Ther. 1986;7(4):163-72.

20. Edouard P, Degache F, Oullion R, Plessis JY, Gleizes-Cervera S, Calmels $P$. Shoulder strength imbalances as injury risk in handball. Int J Sports Med. 2013;34(7):654-60 